\title{
Merging capabilities and livelihoods: analyzing the use of biological resources to improve well-being
}

\author{
Juri Lienert $^{1}$ and Paul Burger ${ }^{1}$
}

\begin{abstract}
Especially poor people in developing countries depend on biological resources to manage their livelihoods and to generate income. Because these resources are usually public goods, their use is often subjected to what is known as the tragedy of the commons, potentially leading to resource depletion, environmental degradation, and loss of biodiversity, which consequently undermines the availability and capacity of resources to contribute to residents' well-being in the long run. We suggest addressing this typical sustainability issue from a new angle. Against the backdrop of identifiable shortcomings within two popular analytic approaches, the capability approach (CA) and the sustainable livelihood approach (SLA), we argue for an improved sustainability framework for analyzing the issue in question. Although we view the CA as encompassing our core ideas regarding human well-being, we propose to enrich it by merging it with the SLA to more adequately include social and environmental capital. To test the framework's usefulness, we apply it to a case study on the use of medicinal and aromatic plants in the rural livelihood context of Nepal. Thereby, we reveal not only that the creation of capabilities is strongly dependent on the set of capital assets available, particularly in the form of natural capital, but also that the framework provides new perspectives: What matters is developing livelihood strategies that increase people's opportunity spaces rather than focusing only on those that compensate for missing capabilities or enable people to cope with shocks and vulnerability.
\end{abstract}

Key Words: capability approach; sustainability analysis; sustainable livelihood approach; use of biological resources; valuation; well-being

\section{INTRODUCTION}

When faced with the ongoing poor and fragile living conditions of a substantial part of humanity and the corresponding need for poverty alleviation, scholars today agree on four general claims. First, the livelihoods in question are strongly based on available biological resources. Second, biological resources are overused on a worldwide level, leading to substantial stress on ecosystems and loss of biodiversity. Third, there are two conflicting claims emerging from claims one and two: The use of biological resources is expected to contribute to reducing poverty, whereas loss of biodiversity calls for conservation. To resolve this conflict, valuation of biological resources should mean to use biological resources sustainably (cf. Tvedt and Young 2007). Fourth, although income is an indicator of poverty, it is an inadequate measure of human well-being. Humans with more income but little access to health and education facilities can be worse off than humans with less income and access to such facilities (Alkire 2007).

Notwithstanding these agreements, scholarly as well as development cooperation approaches include a huge and sometimes conflicting variety, especially regarding how claims three and four are operationalized. A critical issue concerns the underlying understanding of "sustainable." In many cases, the term is used to capture "conservation" rather than the concept of using biological resources sustainably (see, e.g., Miller et al. 2011). Within a Brundtland-like understanding of sustainability, however, the term qualifies "development," directed to improving or safeguarding human well-being, i.e., equity, rather than merely taking into account risks stemming from scarcity of resources and fragility of ecosystems (cf. Meadowcraft 2009). The target according to this understanding is contributing to human wellbeing today by ensuring that future generations also have adequate opportunities to live a humane life (Christen and
Schmidt 2012). According to such a reading, conservation is not the intrinsic goal but is instrumentally directed at requirements of intergenerational justice. Moreover, it has been questioned whether projects on valuation of biological resources really promote poverty alleviation (Ostrom et al. 1999, Suneetha and Pisupati 2009). Hence, and despite the existing general agreement on claims three and four, we view the notion of using biological resources sustainably, as it is propagated by tools such as the Convention on Biological Diversity (CBD) agreement and corresponding follow-ups like the BioTrade Initiative (CBD 1994, UNCTAD 2011), as being in need of conceptual clarification.

Against this backdrop, our main purpose is to pave the way for a new conceptual framework for analyzing the relation between the sustainable use of biological resources and its contribution to sustainable development (SD) in terms of its input toward improving human well-being. Although relying on the capability approach (CA) or the sustainable livelihood approach (SLA) is not new for such an endeavor, the way we link the CA and the SLA is innovative. The scheme we developed especially clarifies means-end relations when talking about the sustainable use of biological resources by giving the well-being of humans today and in future generations center stage. In a first step, we sketch our understanding of "sustainability" with well-being as its core target, i.e., intrinsic goal, as well as our understanding of the CA as a metric of well-being. We critically assess Ingrid Robeyns's (2005) capability framework and draw on the SLA to enrich it. We close the theoretical discourse with a short discussion on some advantages in comparison with other approaches and then present a case study demonstrating the elaborated scheme's empirical usefulness by applying it to a case of the valuation of specific types of biological resources, i.e., medicinal and aromatic plants (MAPs), in the rural livelihood context of Nepal. 


\section{SUSTAINABILITY AND CAPABILITIES AS A METRIC FOR WELL-BEING}

Fully aware of many different scholarly approaches to SD (cf. Kates et al. 2005) and especially of the dominance of "environmental sustainability" perspectives (cf. Liu et al. 2007), we take a clear stance toward an understanding of SD within the Brundtland tradition (WCED 1987). SD is thereby concerned with the safeguarding and development of human well-being, i.e., intra- and intergenerational justice, in a world of fragile systems and finite resources and against the background of complex socioeconomic challenges. SD is about both the current and upcoming generations, i.e., about shaping our future given the substantial risks emerging from our own activities. Although a long-term conservation perspective is a substantial component within such an understanding of $\mathrm{SD}$, the intrinsic value being pursued is human well-being (Kopfmüller et al. 2001, Leßmann 2011, Lessmann and Rauschmayer 2013). Hence, our perspective on SD is an anthropocentric one, even though we look on it as an "enlightened anthropocentrism" (Polishchuk and Rauschmayer 2012, Schultz et al. 2013).

An additional reason supports coupling human well-being and the use of biological resources regardless of our understanding of SD. Conservation is a human activity against the backdrop of other human activities. If sustainability scientists do not take into account well-being-oriented activities within the context of conservation issues, they will most certainly have difficulty contributing to feasible and practical solutions.

In what follows, we assume for the sake of argument the appropriateness of the CA to deliver a metric for well-being within a sustainability framework (cf. the defense in Burger and Christen [2011]). The CA characterizes well-being as the enlargement or preservation of real freedoms available to a human being to realize a valuable life (Sen 1999). According to Sen, this abstract principle finds its best expression in terms of a person's capabilities to achieve the functionings, i.e., the beings and doings, that constitute for him or her a valuable life (Qizilbash 2008). The CA offers an objective and universal metric for well-being capabilities (Nussbaum 2000). Development, then, is about the process of securing or expanding people's capabilities to help them to achieve the lives they value (Ibrahim 2006). Consequently, by using the CA, we consider not only direct benefits in terms of income or goods but also one's general opportunity space to be important for human quality of life and hence for human development.

The CA informs SD in two important respects, namely, regarding its "what to sustain" and "how to sustain" questions (Burger and Christen 2011:789): The metric of well-being gives the basis for clarifying the intrinsic "what to sustain" of SD, namely, the opportunity for all human beings today and in the future to live a valuable life. Furthermore, the CA characterizes people as active agents who are able to bring about change in their own lives. It focuses on societal deliberation regarding what could count as "valuable" and what should be supported by social choices (Sen 1999). Accordingly, importing the CA into a sustainability framework obligates us to have a free agent-oriented, nonpaternalistic stance toward the "how to sustain."

Although the original versions of the CA (Sen, Nussbaum) provide a qualitative metric for well-being, i.e., the evaluation space for development assessments, there are four shortcomings discussed in the literature: First, the CA neglects risks stemming from environmental threats as a problem for current and future generations. Martha Nussbaum (2013) explicitly conceded this point recently. Second, and relatedly, the reciprocal relationship of human-nature interactions is inadequately represented, i.e., the impacts of human action on the ecosystem and their longterm consequences for future generations are not taken into account (Muraca and Voget-Kleschin 2011, Schultz et al. 2013). Third, aspects going beyond the purely individual perspective of quality of life, e.g., the role of the social and cultural dimension, are often underrepresented (cf. Jackson 2005, Ibrahim 2006, Deneulin 2008). Fourth, the CA is vague with respect to putting its principles into practice for an empirical application of the approach (Nussbaum 2000, Alkire 2007).

\section{ROBEYNS'S EXTENDED CAPABILITY FRAMEWORK}

Robeyns's $(2000,2005)$ extended CA framework promises to capture the stated shortcomings. If one is only interested how people are well off, i.e., interpersonal comparison, one can restrict the analysis to capabilities and functionings. If, however, one strives to understand the causes for the corresponding situation and the opportunities for future change, then the scope of analysis has to be widened. Capability spaces beyond the natural endowment usually exist only when they are created. The capabilities for being mobile depend on many factors, such as infrastructure, financial resources, ability to drive, and so forth. Accordingly, there is more to be taken into account than capabilities and functionings only. Moreover, as sustainability is about our future, a scheme is needed that allows for "prospective evaluation" (Alkire 2008) displaying causal means-end relations. Robeyns's framework takes the social and environmental context of an individual into account. Her framework widens the classical structure of commodities/goods, conversion factors, capabilities, and functionings by further including the causal influence of social and environmental factors as mediating elements on conversion factors and on choice. One might accordingly be tempted to interpret her framework as demonstrating the role of society and nature on an individual's well-being, i.e., as taking into account the major desiderata mentioned previously.

Robeyns, however, only broadly defines the input categories for the creation of individual capabilities. Although she refers to central factors such as social norms, institutions, and environmental factors, she does not further qualify them. Three problems emerge from not further clarifying the means/input side. First, infrastructure or facilities are not easily representable along Robeyns's categories: Are they commodities/goods or social context or conversion factors? Although they are obviously important input factors, Robeyns leaves the empirical researcher with a black box and with no analytic guidance in this regard. The second problem emerges when environmental aspects are taken into account as conversion factors only. Water and food are not conversion factors but natural goods, whose availability is an important input for one's opportunity space. Third, her framework is both single directed and purely individualistic, whereas scarcity and fragility are normally effects stemming from aggregated individual actions. Creating opportunity spaces, i.e., through infrastructure, or realizing functionings, e.g., traveling, could generate negative feedback loops for the individuals, e.g., resource depletion. Hence, Robeyns's framework considers neither aggregated effects of individual activities nor their feedback loops on the social and natural enabling factors for capabilities. 
In summary, the standard CA focuses mainly on intrinsic values, i.e., on the morally legitimate evaluative space for individual wellbeing assessment. Sen repeated again and again that the CA is about the ends of human development. Robeyns's extended scheme widened the framework by including social and environmental input factors, i.e., means, as building blocks. Although her scheme points in the direction we are looking for, neither the input factors nor the mechanisms, e.g., feedbacks, are developed in a satisfactory way to serve as guidance for an analysis of the impact of the sustainable use of biological resources on well-being. Although we accept the CA as providing an approach for the intrinsic ends of SD, we are looking for a more adequate approach to capture the input, i.e., means, factors.

\section{THE SUSTAINABLE LIVELIHOOD APPROACH}

There are several plausible reasons for bringing in the SLA. First, the SLA emphasizes what we are looking for, namely, the means of living that an individual necessarily needs to have for his or her well-being. Second, the approach is normatively based "on the ideas of capability, equity, sustainability" (Chambers and Conway 1992:ii). Like the CA, the SLA incorporates a wider understanding of well-being, going beyond economic aspects. Chambers and Conway (1992:6) claim that

... a livelihood comprises the capabilities, assets (stores,
resources, claims and access) and activities required for
a means of living: a livelihood is sustainable which can
cope with and recover from stress and shocks, maintain
or enhance its capabilities and assets, and provide
sustainable livelihood opportunities for the next
generation (...).

Third, the term "sustainable livelihood" refers to the maintenance and enhancement of capabilities both now and in the future, i.e., considers intra- and intergenerational justice. In terms of intragenerational justice, the SLA takes into account social differentiation such as class, ethnic group, gender, and other locally specific social differences. With regard to intergenerational justice, the approach considers the context of fragile natural resources as a driving factor for a sustainable livelihood. Fourth, the SLA claims to be policy guiding and holistic in its way of analysis. Fifth, the SLA emerged primarily from the practical field of development cooperation, and its applicability has already been demonstrated in both projects and corresponding research (Allison and Horemans 2006). As the SLA has a strong normative background generally in line with our core ideas of SD, importing building blocks from the SLA into our endeavor is far from arbitrary.

The standard SLA contains households; their vulnerability context, including uncontrollable events such as shocks and seasonality; and the context of prevailing structures and processes such as policies, laws, and culture that influence a household's livelihood assets base. People choose their livelihood strategies to create intrinsic as well as instrumental livelihood outcomes (Ashley and Carney 1999) against the backdrop of their asset stocks and the prevailing structures and processes. Capital assets build the core of input factors. They go beyond the economic domain and "incorporate the noncommoditized, nonmaterial, and cultural part of life and sets of values that are embedded in local cultural repertoires" (Hebinck and Bourdillon 2002, as cited in Adato and Meinzen-Dick 2002:27). We follow Scoones (1998) and Mancini et al. (2007) and characterize these assets in terms of natural, economic or financial, human, social, and physical capital. However, and despite the attractiveness of this capital assets approach, some caveats need to be addressed.

First, there is an important difference regarding the understanding of capabilities: Capabilities within the SLA refer to the reaction potential to challenges and crises such as climate predicaments, e.g., floods and droughts, and their consequences, e.g., food insecurity (Valdes-Rodriguez and Perez-Vazquez 2011). The CA characterizes them as an individual's opportunity space to attain valuable doings and beings. They are the relevant ends and do not merely demonstrate the ability to react to shocks. We follow the CA and do not upgrade livelihoods to the status of the intrinsic good to sustain.

Second, Chambers and Conway use the term "sustainability" in the sense of linking "long term" and "safeguarding livelihoods." Again, we do not follow that reading. The SLA focuses on negative livelihood effects (Scoones 2009). As a defensive and reactive approach, it fails to emphasize the chances and potentials that active agents, i.e., individuals or households, have, be they induced from external changes or developed as activity portfolios on a grassroots level. The ability to cope with external shocks can only be a subtopic within a justice/well-being-oriented understanding of SD. The SLA's normative background (see Hunsberger et al. 2014) mainly allows for dealing with the intragenerational equity topic "who benefits what." Although intergenerational equity is addressed, it is restricted to local fragility issues and safeguarding livelihoods. The SLA pays much less attention to dynamics of changes related to capitals, institutions, policies, and processes and to prospective livelihood pathways. In this regard, we follow Scoones (2009) in emphasizing the importance of dynamics and a broader scope with respect to sustainability in livelihood frameworks.

Third, it is often stated in the literature that livelihood frameworks do not sufficiently account for power and politics and for the link between livelihoods and governance (Scoones 2009). Despite contributions on livelihood governance (e.g., Hyden 1998) or institutional drivers for change (e.g., DFID 2004), the majority of studies are still focused on the topic of poverty reduction on a local level leaving aside the impact of governance regimes.

\section{A COMBINED LIVELIHOOD-CAPABILITY APPROACH}

As an interim result, we can summarize the argument as follows: SD points to the scarcity of social and environmental resources and the fragility of social and environmental systems as a frame condition for human development. The CA provides us with the intrinsic elements of the evaluative space of human development, leaving the input dimension elaborated unsatisfactorily. The SLA in turn has a narrow normative understanding of "sustainable" and an ambiguous understanding of capabilities but offers a wellestablished approach for the instrumental input factors left open by the CA. Moreover, the debate on governance of sustainable development (see Lafferty 2004, Meadowcraft 2009, Lange et al. 2013) points to the importance of governance issues (cf. Neupane et al. [2012] for the relevance of governance for the whole project from which our work has emerged). Table 1 gives an overview of these strengths and weaknesses together with the expected addons in merging them. 
Table 1. Overview of the strengths and weaknesses of the approaches discussed.

\begin{tabular}{|c|c|c|c|}
\hline $\begin{array}{l}\text { Standard Capability Approach } \\
\text { (CA) }\end{array}$ & $\begin{array}{l}\text { Extended Capabilities } \\
\text { Framework }\end{array}$ & $\begin{array}{l}\text { Sustainable Livelihood } \\
\text { Approach (SLA) }\end{array}$ & Our Merged CA-SLA Model \\
\hline \multicolumn{4}{|l|}{ Strengths } \\
\hline Strong normative background & $\begin{array}{l}\text { Acknowledges other factors as } \\
\text { decisive means for attaining } \\
\text { normative ends }\end{array}$ & $\begin{array}{l}\text { Instrumental importance: capital } \\
\text { assets as decisive means for well- } \\
\text { being }\end{array}$ & $\begin{array}{l}\text { Can fill the black box of } \\
\text { conversion factors left by } \\
\text { Robeyns }\end{array}$ \\
\hline $\begin{array}{l}\text { Consideration of } \\
\text { intergenerational justice }\end{array}$ & $\begin{array}{l}\text { Incorporates the influence of } \\
\text { societal structures on individual's } \\
\text { well-being }\end{array}$ & $\begin{array}{l}\text { Takes feedback loops into } \\
\text { account }\end{array}$ & $\begin{array}{l}\text { Combination between means and } \\
\text { capabilities as ends of human } \\
\text { well-being }\end{array}$ \\
\hline $\begin{array}{l}\text { Universally applicable metric of } \\
\text { quality of life } \\
\text { Characterizes people as active } \\
\text { agents }\end{array}$ & & Has proved its applicability & $\begin{array}{l}\text { Provides sufficient analytic } \\
\text { dimensions }\end{array}$ \\
\hline \multicolumn{4}{|l|}{ Weaknesses } \\
\hline $\begin{array}{l}\text { Weak consideration of social } \\
\text { and collective dimensions } \\
\text { Weak consideration of } \\
\text { environmental aspects }\end{array}$ & $\begin{array}{l}\text { Only broadly defines inputs for } \\
\text { the creation of capabilities } \\
\text { Leaves the meaning of } \\
\text { conversion factors relatively } \\
\text { open }\end{array}$ & $\begin{array}{l}\text { Ambiguous understanding of } \\
\text { capabilities as means and ends } \\
\text { Weak normative understanding }\end{array}$ & $\begin{array}{l}\text { Empirical usefulness not yet } \\
\text { sufficiently demonstrated }\end{array}$ \\
\hline Single directed & $\begin{array}{l}\text { Environmental aspects are only } \\
\text { considered as conversion factors }\end{array}$ & $\begin{array}{l}\text { Narrow understanding of } \\
\text { "sustainable" }\end{array}$ & \\
\hline \multirow[t]{2}{*}{ Empirical applicability } & No feedback loops considered & $\begin{array}{l}\text { Weak consideration of power, } \\
\text { politics, and governance }\end{array}$ & \\
\hline & $\begin{array}{l}\text { Gives no concrete directions for } \\
\text { an empirical application }\end{array}$ & & \\
\hline
\end{tabular}

The combined approach is based on strengths in a way that the weaknesses can be mutually compensated. Accordingly, the building blocks are (1) the capabilities and functionings as relevant evaluative space for well-being, i.e., as ends; (2) capital assets; (3) the prevailing social, economic, and natural environment on the macro- and microlevel; (4) individual conversion factors; (5) choices and livelihood strategies; and (6) feedback loops displaying intergenerational concerns. The relations between these building blocks are as follows: Capital assets are direct input factors for one's capability space; macroconditions build the broader opportunity space, and microconditions impact choices and livelihood strategies. The combined scheme is shown in Figure 1.

\section{ADVANTAGES OF THE LIVELIHOOD-CAPABILITY PERSPECTIVE}

What are the advantages of our framework in relation to other approaches for analyzing SESs, such as, for example, Ostrom's SES (Ostrom 2009) or the Millennium Ecosystem Assessment (MEA) (2005) both linking human well-being and environmental issues? Without claiming to provide a satisfactory discussion on the different strengths and weaknesses, we want to close the theoretical discussion with some comparative statements.

First, and most importantly, the focus of our framework is not environmental management or ecosystem assessment but human well-being. Our scheme is thought to provide a tool for analyzing possible impacts from valuation of biological resources on wellbeing that overcomes the shortcomings listed previously. Hence, we have a different perspective, i.e., research interest, than the SES or the MEA, the first of which is directed to understanding conditions for preventing overuse of the commons and the second of which is directed to understanding the impact of ecosystem degradation on human well-being.
Second, and related to the first, we want our framework to be based on a normative approach that is well established and also prominently used especially in a development context: the CA. Neither Ostrom nor the MEA is committed to such a normative approach. Although the MEA refers to people's freedom to live a valuable life, the report does not operationalize it and is mainly focused on demonstrating negative impacts from environmental degradation.

In line with Ostrom but contrariwise to the MEA, we take an agent-oriented, or action-oriented, perspective also paying attention to agent-structure relations. However, Ostrom is mainly interested in frame conditions for collective action, i.e., governance, whereas we only point to the systematic place governance has without really analyzing it.

Accordingly, there are many interfaces depending on one's knowledge interest. We must leave it to further research to determine how these interfaces could be made useful for empirical research, e.g., how ecosystem service analysis or success conditions for collective action can be imported into our framework.

\section{EMPIRICAL APPLICATION}

In the following, we present a case study of three villages in mountain and hill regions in western Nepal. It was conducted to serve two explorative means, namely, (1) to determine whether and how the framework can be used empirically and (2) to look at the possible impacts of MAPs on well-being. The first objective takes center stage. The case study will primarily serve to validate the framework. Validity is prior to reliability (Mayring 2010). Following this principle, it is not the aim of this empirical discussion to deliver highly elaborated empirical results on 
Fig. 1. A livelihood-based capabilities framework from a sustainability perspective.

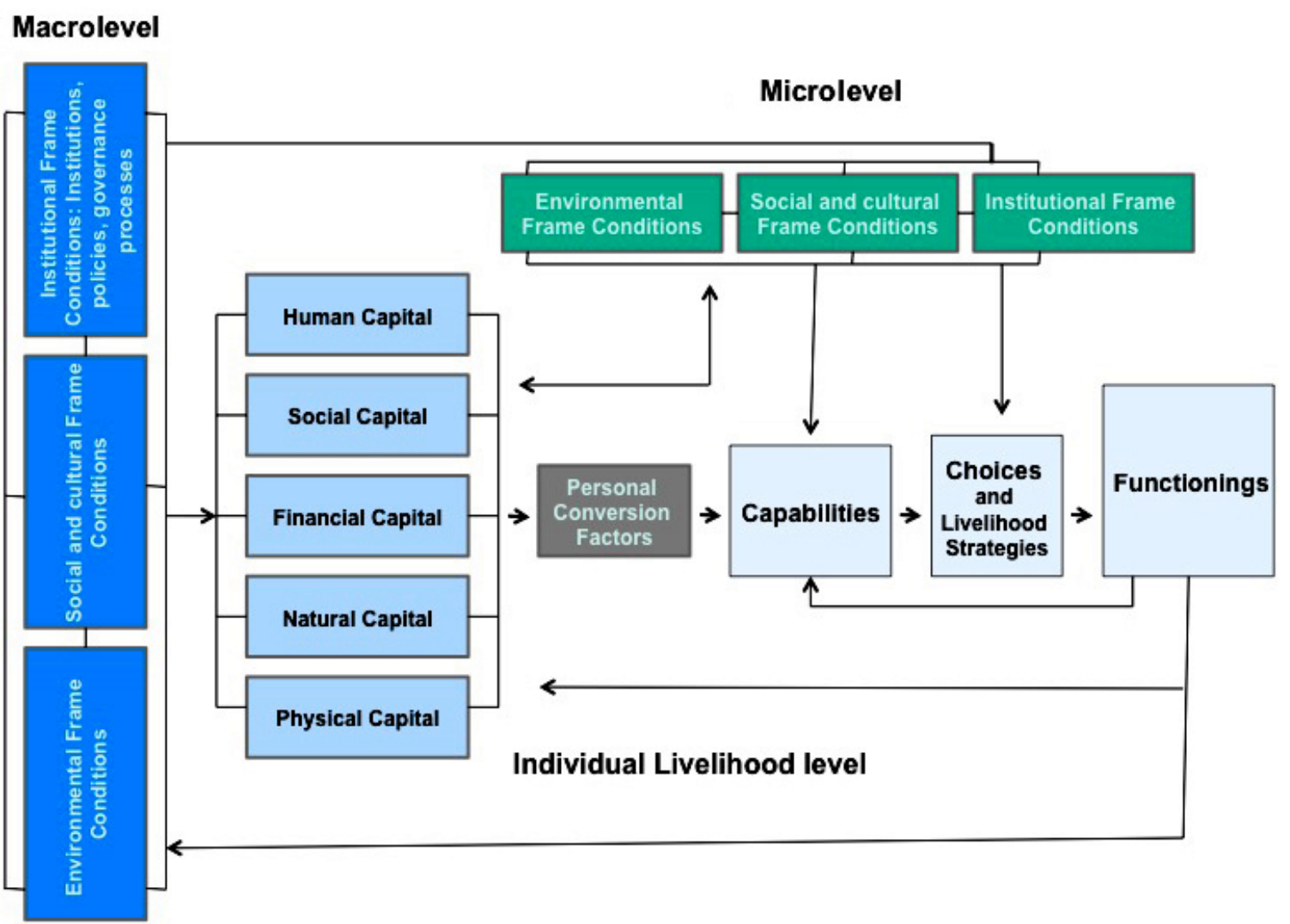

sustainable valuation, but rather to first test the validity of the developed framework in an empirical sustainability setting.

\section{The sustainability issue: use of and trade in biological resources in Nepal}

Nepal, with its great variety of geographic areas, possesses about 1800 species of plants, including a large number of MAPs and other nontimber forest products (NTFPs) (Jenisch and Probst 2011). MAPs and NTFPs are an integral part of local communities' livelihoods (Olsen and Bhattarai 2005). Moreover, the international market for MAPs and NTFPs has developed rapidly. Products from the Himalayan region are highly valued, for instance, as inputs for modern and natural medicines or for food. Hence, the use of these biological resources creates opportunities for production, trade, and commercialization to improve living conditions for people in rural Nepal (cf. Adhikari et al. 2004).

The issue in question demonstrates the qualities stated previously: (1) People in rural Nepal are highly dependent on the availability of NTFPs and MAPS. Most of these resources are collected. (2) Resources are intensely (over-)used, causing loss of biodiversity and habitat destruction. As a consequence, (3) the use of MAPS and NTFPs as part of livelihood strategies stands in conflict not only with conservation but also, from an intergenerational perspective, with the livelihood strategy itself, i.e., depletion of resources. Accordingly, (4) a sustainability-oriented strategy calls for a new type of use that considers human well-being, society, and nature adequately. The last point is beyond our scope. What we can and will do is to reveal how the collection of MAPs and NTFPs currently creates benefits in terms of capabilities or, more appropriately, in terms of our framework in question.

The case study sites

We carried out the case study in three remote villages in mountain and hill regions in rural Mid-Western and Far-Western Nepal. Whereas these regions possess a high density of biodiversity and receive the second highest revenue in Nepal from collection of NTFPs and MAPs (Jha et al. 2008), they belong to the least developed regions in Nepal (Jenisch and Probst 2011). This paradox makes the area interesting for our topic in question, expressing the tension between human well-being and the use of highly valued biological resources. The study sites are Bata, a village in the lower mountain area of Jumla; Badegoan, a village in the higher hill area in Bahjang; and Jumlepani village in the lower hill area in Dang. The sites represent three typical geographic areas in Nepal.

\section{Developing a category system: operationalization of the framework}

The primary analytic task consisted of translating the elaborated framework into a transparently comprehensible empirical setting. Questionnaires and interview guidelines needed to illustrate the logic of our framework. For developing both the interview baseline in the form of qualitative interview guidelines and a system for the following data analysis, we decided to use a 
qualitative content analysis according to Mayring (2010) and Kelle and Kluge (2010). Along with that, we developed and coded a category system. We formulated a priori and a posteriori categories and subcategories illustrating our framework. The data analysis included both the aggregation of statements with the aim to emphasize the essential data content and the explication of interview passages to exemplify the meaning of single statements.

The first step consisted of clarifying our empirical understanding of "capabilities." Following Sen (1999), measuring well-being focuses on what set of capabilities a person has in terms of real opportunities for realizing valuable functionings. However, a priori selecting well-being criteria, or poverty dimensions, is problematic insofar as there are no general criteria available for what could count as "valuable." Accordingly, Sen (1999) and Alkire (2007) both claim that these dimensions should be defined in a deliberative process that incorporates individual opinions. Unfortunately, such public opinion-based, bottom-up approaches for selecting the valuable dimensions of well-being are extremely difficult to carry out. Hence, we decided to use Nussbaum's list of central capabilities as an orientation in finding dimensions that matter for human well-being. We understand Nussbaum's work not as a listing of single capabilities, but rather as expressing the most valuable dimensions of capabilities, each of them representing a central domain for a good human life.

The second step involved the operationalization of the SLA capitals. We took the asset pentagon as a starting point. Accordingly, five categories for each asset type were set up. Questions concerning the state of livelihood assets were derived, including the impact of the use of biological resources on those livelihood enablers. For instance, with respect to social capital, we asked about the interviewees' social relationships, their experiences in social life, and how social determinants such as community membership have an impact on other capital resources such as the access to natural resources.

Strategies in the SLA and choices in the CA, which we consider to be connected in our framework in a functional understanding stemming from the SLA and an intrinsic understanding stemming from the CA, determine what kind of livelihood and well-being outcomes, i.e., functionings, a person will achieve. Strategies are operationalized as activities that people choose to undertake to achieve their livelihood goals (DFID 1999). At the same time, our understanding follows the $\mathrm{CA}$ in allowing people to make different choices following their ideas about what constitutes a good life (Robeyns 2005).

Macro- and microlevel frame conditions are complex and multidimensional; they consist of a long list of factors, some of them influenced on a livelihood level and some of them simply given and not alterable. Micro- and macrolevel frame conditions are understood as the local enabling and disabling factors in terms of politics, power, institutions, culture, environment, religion, caste, and other factors. However, because these frame conditions were not our primary object of concern, we only point to them insofar as there are important relations to other factors within our scheme.

\section{Developing the questionnaire}

The questionnaire for the in-depth interviews, in which we tried to rope in the complex connection between livelihood input and well-being impact factors, was designed according to that operationalization. For the asset pentagon, we formulated questions regarding human capital, i.e., level of education, level of training, knowledge of NTFPs and biotrade, health, and physical ability; physical assets, i.e., type of house, water supply, and sanitation; financial assets, i.e., monthly income, savings, and loans; natural capital, i.e., water, land, fodder, and climate change; and social capital, i.e., social relationships such as family and friends, memberships in groups, and relationship to neighbors and the village.

For livelihood strategies, we asked questions about how people invest their available livelihood assets and capability spaces for creating well-being functionings, such as generating an income or sending their children to school. Our specific interest concerned those activities related to the use of NTFPs.

Because we have already had challenging experiences in applying the CA in an interview context (Lienert 2011), we decided to keep the questionnaire about the well-being dimensions relatively open. For instance, for the dimension bodily health, we asked the respondents to give a general outlook on their health and nutrition situation. As a backup, we had a range of specific questions that we asked in those cases in which respondents hesitated to answer directly. Although we had no problem getting answers for some of the dimensions, i.e., bodily health and control over one's environment, there were other dimensions for which respondents had difficulty expressing themselves or did not comprehend the meaning of the question, i.e., emotions and practical reasons.

\section{Interview methods}

Field research with the corresponding interviews was carried out in February 2012. The data collection was conducted using qualitative in-depth interviews and qualitative participatory methods. A total of 15 in-depth interviews were carried out at the household level, evenly distributed over the 3 villages. The interviewees were 9 women and 6 men with an average age of 36 years. We reserved the option to utilize a one-sided sample such as uneven male-female proportion, age distribution, and caste affiliation by applying theoretical sampling and the method of contrasted cases (Kelle and Kluge 2010). However, the sample selection was partly at random dependent on the availability of interview partners in the given time window. Methods for in-depth interviews were applied according to Flick (2012) and Mack et al. (2005). In addition to in-depth-interviews, two focus group interviews and three community workshops were carried out to expand the perspective from households to the community level. Those took place in public meeting points such as schools or market places. For the community workshops, all villagers were invited to participate, whereas the focus groups again were theoretically sampled. The focus groups and the community workshops took one to two hours. For carrying out the focus groups and the community workshops, a guideline was developed according to the methods of Gibbs (1997).

In addition, particularly to describe relevant microlevel frame conditions, nine unstructured open interviews with stakeholders and experts in the region were conducted. This helped us to get to know the local context and to gain additional information. Furthermore, key informant interviews were carried out at each study site using a semistandardized questionnaire for gathering information about livelihood conditions on a community level. After data collection, all interviews were translated from Nepali to English and transcribed. 


\section{FINDINGS AND INTERPRETATION}

\section{Introducing the macrolevel frame conditions}

The forest represents one of the few opportunities for people to generate income and to find inputs for sustaining their livelihoods in Nepal beyond subsistence agriculture. However, the decline of forests, and along with that a loss of biodiversity, is one of the major concerns associated with this central opportunity space of local people. The government of Nepal has reacted to the alarming decline of natural conditions by introducing a wide range of policies and regulations. The Forest Act passed in 1993 (see Gautam et al. 2004) regularizes the most critical issues regarding benefit and access to forest resources including timber products and NTFPs. The act recognizes the rights of selfgovernance, self-management, and utilization of forests and bases Nepal's forest management system on community-based forest management and its community-based forest user groups (CFUGs) as central actors (Ojha et al. 2007). In terms of social and cultural conditions, Nepal has a very heterogeneous society with a complex mix of ethnic groups (see Bista 1991). Religion and family are still central features of Nepali life. In the absence of any social security features from the central government, family represents the social safety net (Khanal 2013).

\section{The capital assets}

\section{Physical capital}

Two of the three villages are located in remote mountainous areas, only accessible by foot with road connection within walking distance of five and two hours, respectively. One village is connected to a road. Only two villages have access to electricity; in one village, people have simple solar panels available in a few households. Those missing infrastructural services limit considerably the capabilities space of the respondents. For instance, the opportunity for education is limited to the schools and training centers that can be reached within walking distance. People live in simple stone-built houses; in Bahjang, improved stoves financed by external aid exist. In the other two villages, people have traditional open fireplaces inside their houses. Some respondents complained about respiratory problems: hence, the capability dimension bodily health is also limited by those infrastructural shortcomings. All villages have health posts within walking distance of less than two hours. Hospitals can be reached within five hours' walking distance; however, the access to these health facilities is difficult, especially for elderly, ill, and disabled people. In many cases, lack of financial means constrains whether people get medicated. Water is provided over public stand posts. No household has its own water tap. In two villages, all households are provided with improved sanitation facilities in the form of ventilated twin-chamber pit latrines from a foreign nongovernmental organization. In one village, people have simple pit latrines and go for open defecation. This lack of basic water and sanitation facilities affects not only the health situation of the respondents but also other related capability dimensions such as their bodily integrity.

\section{Human capital}

Respondents have a low state of education. The majority of women are illiterate, whereas the majority of male respondents went to primary school and are literate. Hardly anyone has a professional education apart from training courses given as capacity building when new development initiatives were introduced. The amount, level, and intensity of such training strongly varies and seems to depend on how well the community is organized in terms of exercising its rights for getting external support. No training activities were carried out in the specific field of use and trade in biological resources. However, people do have a relatively high level of traditional knowledge of biological resources, which is disseminated from generation to generation. Most of this knowledge concerns their direct use as food or for medicinal purposes. Biotrade knowledge, however, is limited to collection and drying. Education and knowledge, the most fundamental capability dimensions, are weakly developed among the respondents. Reasons for the lack of education are manifold; for instance, basic physical and financial capitals are not prevalent for a better state of education. Human capital for biotrade is limited as well; this in turn confines both the development and the carrying out of livelihood strategies related to biotrade.

\section{Natural capital}

Basically, most of the respondents showed satisfaction with the availability of natural capital. However, land availability was stated to be a critical issue because some people hold no or very little land. In addition, people lack water availability for agriculture during the dry season because no irrigation systems have been installed. Furthermore, respondents emphasized the dwindling of accessible natural capital in Jumla and the increase of available natural capital in Bahjang. We found that availability of natural resources was connected to local natural resource management. Natural capital was assessed as one of the central capital stocks by the respondents in terms of agriculture for selfconsumption or subsistence farming, collecting NTFPs in the forests, or the allocation of necessary daily products such as fodder or firewood. Natural capital is thus central for the respondents to fulfill basic livelihood conditions. However, the interviewees also reported serious issues regarding the limited availability of natural resources because of unforeseen events such as droughts or shrinking forests, leading to a shortfall of the goods on which people are dependent.

\section{Financial capital}

People significantly lack income-generating opportunities. Although all the interviewed households relied on agriculture for self-supply, the volume of harvest was not sufficient to provide food year-round or to sell enough products to have sufficient income. The regular source of income was mainly provided through labor migration. Usually, male members of a household stayed in the village during the fertile rainy season to work in agriculture and stock farming and left for labor work during the dry winter season for three to six months. This was stated in all three villages as the only option for providing families with sufficient financial means to sustain their livelihoods. In contrast, the income from MAPs contributed to financial capital only to a minor degree. The lack of income opportunities results in a very limited basis of savings. Some respondents stated their concerns about not being able to react in times of crisis, such as a crop failure or serious illness. In a crisis situation, respondents refer to family and friends as supporting institutions in case of emergency to overcome vulnerability. 


\section{Social capital}

Respondents emphasized group membership in the CFUG as crucial because it enabled them to take part in a network in which general issues regarding the use and trade of biological resources as well as topics of forest conservation were discussed. Women looked on the membership as an important opportunity for empowerment, to gather with others and to share their concerns in a place where they can freely interact. "We get together and discuss on how we can do something, how we can benefit" (respondent in Jumla). Moreover, participation in the CFUG also seems to serve as a motivating factor for people to engage in other initiatives. In addition, family, friends, and the village with its inhabitants have been stated as important sources of social capital.

\section{Microlevel frame conditions}

People in the three villages depend on natural resources. Local natural frame conditions and available natural resources are the main materialistic livelihood assets for the respondents, not only in terms of income but also as the basis for agriculture and therefore for basic nourishment, stockbreeding, using firewood as an energy source, and providing basic remedies for health care. In all villages, people expressed a strong relationship to nature and a high awareness of the interdependency between human action and nature. Respondents were aware of the effects of local human activities on their natural conditions. In Jumla, overuse led to a degradation of natural resources in past years in a landscape where livelihood conditions are already harsh because of its geographic exposure. As one consequence, people have to walk long distances up to 12 hours to collect firewood and fodder. The need to invest more time to cover basic needs results in high opportunity costs such as the inability to enjoy education or to invest in income-generating activities. Hence, people emphasized not only the use of resources but also conservation as a highly recognized issue. Respondents stated that the maintenance of intact environmental frame conditions serves as a precondition for an individual's livelihood and well-being: "We need to protect our forest. If the forest dies, there will be no water and we need to go far to fetch it (...). We cannot live without the forest" (respondent in Jumla).

In all three villages, forest management was carried out over a CFUG. However, CFUGs vary significantly with regard to their performance, forms of participation, and the derived benefits. The best case example has been found in Bahjang, where an income of 1.5 million Nepalese rupees is generated annually through CFUG activities and is partly invested in community development activities such as public sanitation, drinking water, and irrigation systems. The group also has a microcredit system in which members can borrow money according to their state of income. The membership in a CFUG is seen as important in all three villages for several reasons: First, both the use and the conservation of biological resources has improved through the CFUG management. Second, and as a consequence, people can enhance their income opportunities through a membership. Third, respondents see the chance to improve their social capital through a membership in the CFUG. These statements about natural resource management illustrate that the successful implementation of CFUGs, and along with that a high degree of self-organization, creates a favorable structural setting that particularly improves the situation of respondents' livelihood capitals situation. However, the distribution of power seems to be unequal at the microlevel: Not all castes were represented in all CFUGs, and a few respondents criticized their exclusion from decision making as well as from general participation in the CFUG.

\section{Livelihood strategies and central capabilities}

Among Nussbaum's 10 capability dimensions, we found that bodily health, bodily integrity, other species, and affiliations stood in central relation to the valuation of biological resources. Within the dimensions bodily health and bodily integrity, respondents pointed out that they do not suffer from food shortages or health problems under normal circumstances. However, the occurrence of a crisis can cause drastic imbalance in their livelihood situation. In such cases, options for solutions are significantly lacking because of the fact that opportunity spaces are already quite narrow under normal circumstances. Many examples were reported in which an unforeseen occurrence triggered a domino effect leading to a loss of central valuable capabilities. For example, a widow in Jumla told the story of losing her husband because of an accident during herb collection. Subsequently, the young mother of two children had serious problems providing for her family properly, and after a while, she was no longer able to send the older child to school.

Regarding the dimension other species, respondents expressed concerns directly related to the use of NTFPs and MAPs. The fact that they are collected by almost everyone increases the risk of overuse and thereby increases the risk of losing one of the rare income-generating activities. Accordingly, respondents consider conservation to be a most important requirement because natural resources with their provided services are the basis for many livelihood activities. Beyond this, interviewees mentioned that an aesthetic as well as moral connection to nature belonged to their understanding of a good life.

The capability dimension affiliation was reported to take center stage in the respondents' life. Family was considered to give people a reason to live. On the one hand, there is a practical reason that makes affiliation so important: Family represents the social safety net for respondents. On the other hand, it involves sharing love and pleasure, spending leisure time with family and friends, celebrating festivals, making the important decisions of life, and sharing happiness as well as sorrow. "Without family, there is no reason to live for me" (respondent in Bahjang). People considered social affiliation-related capabilities as significant to compensate for otherwise lacking capabilities. Affiliations were valued as most important for respondents' lives: In times of crisis, such as sickness, financial problems, or lack of manpower, family and friends provide support.

\section{Interpretation}

Our analysis reveals that MAPs and NTFPs are central assets for individuals' livelihoods in terms of food and nutrition, livestock, energy, income, health, and so forth. Despite their relevance, however, they are not plentiful enough to sustain individuals' livelihoods. Nevertheless, because of a lack of alternative livelihood strategies, the use and sale of collected MAPs and NTFPs remains one of the most important livelihood options. Regardless of widespread consciousness about protection requirements, it seems to be part of individuals' livelihood strategies to optimize the use of natural assets. On the aggregated 
level, this increases the risk of overuse of the existing resources. So far, our analysis revealed no new insights. However, by linking the SLA with the CA, we have been able to shed new light on the topic of analyzing the use of biological resources for well-being.

First, the evaluation of central capabilities has shown that not all central capability dimensions are sufficiently developed. Accordingly, we are talking not only about vulnerability but also about deprivation. Even if compensating for lacking capabilities by using social affiliations as well as social capital leads to a state of satisfaction among the villagers, the CA's moral background demand is for not only the compensation of missing capabilities but also the creation of freedoms in all relevant domains and therefore for the abolishment of deprivation. The object of concern is deprivation, vulnerability being only a part of it. Hence, the central normative question is how people can expand their capability space. Second, the respondents are compensating for deficits of central capabilities by creating, maintaining, and utilizing social capital and the capability dimension social affiliations. Missing capital assets, i.e., financial capital, are being substituted by other capital forms, i.e., natural capital and social capital. Accordingly, our scheme also allows detecting the prevailing interplay between the different factors within and across the dimensions. Third, social affiliations as well as the capability dimension other species also play an intrinsic and moral role in people's understanding of a good life. The according assets, e.g., the forest or family, are regarded not only as the means to achieve ends but also as valuable ends in themselves. Hence, the analysis along the framework sheds light on the complex relation between means and ends that the SLA also takes into account. Capitals can be perceived both as instrumental and as intrinsically valuable. Fourth, the creation of capabilities is strongly dependent on the set of capital assets available. Managing natural capital for both use and conservation is thus even more important. The availability of capital assets is identified as a precondition for achieving well-being. The people interviewed strongly emphasized that the existing livelihood strategies for creating such freedoms were significantly unsatisfactory. Fifth, accordingly, the hitherto established use of MAPs, i.e., collecting and drying, rarely has the potential to be developed into new livelihood strategies, even if well managed by CFUGs. Strategies for sustainable use of MAPs may take into consideration not only the conservation aspects but also how the according use really contributes to enhancing people's capability spaces.

\section{DISCUSSION AND CONCLUSION}

By merging the CA with the SLA, we have been able to open up a new perspective for analyzing such types of sustainability issues from a conceptual point of view. In addition, the empirically established five points discussed previously go beyond what either the CA alone or the SLA alone would have been able to reveal. We enriched the perspective of the resilience-focused SLA by emphasizing the importance of agency and the creation of opportunity spaces as a normatively justified target domain. The integration of the more practical perspective of the SLA into the CA allowed us to achieve empirical results not only on the current living conditions but also on causes of deprivation together with clues for prospective approaches to overcome deprivation. By considering both capabilities and assets, the relationship between the means and ends of living could be shown. Our analysis thus illustrates the complex relationship between the availability of natural resources, their use and management, and consequences for people's state of well-being on a microlevel from a new angle by conceptually coupling two major approaches in human development issues. In particular, we revealed the importance of social capital and social affiliation-related capabilities to compensate for lacking central capabilities. Moreover, improved livelihood strategies should not only concentrate on the sustainable use of MAPs in terms of collection but also include new options, e.g., for cultivating or processing.

We view the established theoretical consistency in linking the CA and the SLA for a sustainability perspective and its demonstrated empirical usefulness as strengths. However, open questions certainly remain. Our empirical analysis faces several limitations. First, the three explorative case studies do not deliver representative results; this lies in the nature of qualitative research. In addition, we did not try to inductively improve the framework against the backdrop of our sample. Second, the fact that the interviews were carried out in Nepali and translated into English involves well-known risks in terms of possible biases. Third, we only focused on established livelihood strategies and revealed their inadequacy, i.e., collecting and drying as a contributing but not as a substantially contributing factor. We did not analyze possible alternatives but did later on within the project. Notwithstanding those still existing weaknesses, however, we hope with this scheme to have opened the floor for new perspectives in upcoming studies, both in research on the use of biological resources and in related empirical sustainability research.

Responses to this article can be read online at: http://www.ecologyandsociety.org/issues/responses. $\mathrm{php} / 7405$

\section{Acknowledgments:}

We thank Susette Biber-Klemm (University of Basel) and Laxman Neupane (Sanskrit University, Nepal) for their valuable suggestions and help during the fieldwork. We also acknowledge two anonymous reviewers for their constructive input, which helped improve this manuscript.

\section{LITERATURE CITED}

Adato, M., and R. Meinzen-Dick. 2002. Assessing the impact of agricultural research on poverty using the sustainable livelihoods framework. Environment and Production Technology Division Discussion Paper 89. International Food Policy Research Institute, Washington, D.C., USA

Adhikari, B., S. Di Falco, and J. C. Lovett. 2004. Household characteristics and forest dependency: evidence from common property forest management in Nepal. Ecological Economics 48 (2):245-257. http://dx.doi.org/10.1016/j.ecolecon.2003.08.008

Alkire, S. 2007. Choosing dimensions: the capability approach and multidimensional poverty. Pages 89-119 in N. Kakwani and J. Silber, editors. Many dimensions of poverty. Palgrave Macmillan, New York, New York, USA. 
Alkire, S. 2008. Using the capability approach: prospective and evaluative analyses. Pages 26-50 in F. Comim, M. Qizilbash, and S. Alkire, editors. The capability approach. Concepts, measures and applications. Cambridge University Press, New York, New York, USA. http://dx.doi.org/10.1017/CBO9780511492587.002

Allison, E. H., and B. Horemans. 2006. Putting the principles of the sustainable livelihoods approach into fisheries development policy and practice. Marine Policy 30(6):757-766. http://dx.doi. org/10.1016/j.marpol.2006.02.001

Ashley, C., and D. Carney.1999. Sustainable livelihoods: lessons from early experience. Volume 94. Department for International Development, London, UK.

Bista, D. B. 1991. Fatalism and development: Nepal's struggle for modernization. Orient Blackswan, Hyperabad, India.

Burger, P., and M. Christen. 2011. Towards a capability approach of sustainability. Journal of Cleaner Production 19(8):787-795. http://dx.doi.org/10.1016/j.jclepro.2010.06.019

Chambers, R., and G. R. Conway. 1992. Sustainable rural livelihoods: practical concepts for the 21st century. Institute of Development Studies (IDS) Discussion Paper 296. IDS, University of Sussex, Brighton, UK.

Christen, M., and S. Schmidt. 2012. A formal framework for conceptions of sustainability - a theoretical contribution to the discourse in sustainable development. Sustainable Development 20(6):400-410. http://dx.doi.org/10.1002/sd.518

Convention on Biological Diversity (CBD). 1994. Convention on Biological Diversity. Secretariat, CBD, Montreal, Canada.

Deneulin, S. 2008. Beyond individual freedom and agency: structures of living together in the capability approach. Pages 105-124 in F. Comim, M. Qizilbash, and S. Alkire, editors. The capability approach. Concepts, measures and applications. Cambridge University Press, New York, New York, USA. http:// dx.doi.org/10.1017/CBO9780511492587.005

Department for International Development (DFID). 1999. Sustainable livelihoods guidance sheets. DFID, London, UK.

Department for International Development (DFID). 2004. Drivers of change. Public Information Note. DFID, London, UK. [online] URL: http://www.gsdrc.org/docs/open/DOC59.pdf

Flick, U. 2012. Handbuch qualitative Sozialforschung. Psychologie Verlagsunion, Weinheim, Germany.

Gautam, A. P., G. P. Shivakoti, and E. L. Webb. 2004. A review of forest policies, institutions, and changes in the resource condition in Nepal. International Forestry Review 6(2):136-148. http://dx.doi.org/10.1505/ifor.6.2.136.38397

Gibbs, A. 1997. Focus groups. Social Research Update 19. [online] URL: http://sru.soc.surrey.ac.uk/SRU19.html

Hunsberger, C., S. Bolwig, E. Corbera, and F. Creutzig. 2014. Livelihood impacts of biofuel crop production: implications for governance. Geoforum 54:248-260. http://dx.doi.org/10.1016/j. geoforum.2013.09.022

Hyden, G. 1998. Governance and sustainable livelihoods: challenges and opportunities. University of Florida, Gainesville, Florida, USA.
Ibrahim, S. S. 2006. From individual to collective capabilities: the capability approach as a conceptual framework for self-help. Journal of Human Development 7(3):397-416. http://dx.doi. org/10.1080/14649880600815982

Jackson, W. A. 2005. Capabilities, culture and social structure. Review of Social Economy 63(1):101-124. http://dx.doi. org/10.1080/00346760500048048

Jenisch, T., and T. Probst. 2011. Medicinal and aromatic plants: poverty impact assessment (PIA) of proposed trade support measures in Nepal's medicinal and aromatic plants sector. Deutsche Gesellschaft für Internationale Zusammenarbeit, Kathmandu, Nepal.

Jha, P. K., S. B. Karmacharya, M. K. Chettri, C. B. Thapa, and B. B. Shrestha. 2008. Medicinal plants in Nepal. Ecological Society, Kathmandu, Nepal.

Kates, R. W., T. Parris, and A. Leiserowitz. 2005. What is sustainable development? Goals, indicators, values and practice. Environment 47:8-21.

Kelle, U., and S. Kluge. 2010. Vom Einzelfall zum Typus: Fallvergleich und Fallkontrastierung in der qualitativen Sozialforschung. Springer Verlag, Wiesbaden, Germany. http:// dx.doi.org/10.1007/978-3-531-92366-6

Khanal, D. R. 2013. Social security/social protection in Nepal: situation analysis. International Labour Organization Country Office for Nepal, Kathmandu, Nepal. [online] URL: http:// staging2.ilo.org/wcmsp5/groups/public/---asia/---ro-bangkok/---ilokathmandu/documents/publication/wcms_216490.pdf

Kopfmüller, J., V. Brandl, J. Jörissen, M. Paetau, G. Banse, R. Coenen, and A. Grunwald. 2001. Nachhaltige Entwicklung integrativ betrachtet, Konstitutive Elemente, Regeln und Indikatoren. Edition Sigma, Berlin, Germany.

Lafferty, W. 2004. Governance for sustainable development: the challenge of adapting form to function. Edward Elgar, Cheltenham, UK.

Lange, P., P. P. J. Driessen, A. Sauer, B. Bornemann, and P. Burger. 2013. Governing towards sustainability - conceptualizing modes of governance. Journal of Environmental Policy \& Planning 15 (3):403-425. http://dx.doi.org/10.1080/1523908X.2013.769414

Leßmann, O. 2011. Sustainability as a challenge to the capability approach. Pages 43-61 in F. Rauschmayer, I. Omann, and J. Frühmann, editors. Sustainable development. Capabilities, needs, and well-being. Routledge, London, UK.

Lessmann, O., and F. Rauschmayer. 2013. Re-conceptualizing sustainable development on the basis of the capability approach: a model and its difficulties. Journal of Human Development and Capabilities 14(1):95-114. http://dx.doi.org/10.1080/19452829.2$\underline{012.747487}$

Lienert, J. 2011. Assessing Ecosan in the context of quality of life: a case study about the introduction of Ecosan in Bhutan. Thesis. University of Basel, Basel, Switzerland.

Liu, J., T. Dietz, S. R. Carpenter, C. Folke, M. Alberti, C. L. Redman, S. H. Schneider, E. Ostrom, A. N. Pell, J. Lubchenco, W. W. Taylor, Z. Ouyang, P. Deadman, T. Kratz, and W. 
Provencher. 2007. Coupled human and natural systems. $A M B I O$ 36:639-649. http://dx.doi.org/10.1579/0044-7447(2007)36[639:CHANS] 2.0.CO;2

Mack, N., C. Woodsong, K. M. MacQueen, G. Guest, and E. Namey. 2005. Qualitative research methods: a data collector's field guide. Family Health International, Durham, North Carolina, USA.

Mancini, F., A. H. C. Van Bruggen, and J. L. S. Jiggins. 2007. Evaluating cotton integrated pest management (IPM) farmer field school outcomes using the sustainable livelihoods approach in India. Experimental Agriculture 43:97-112. http://dx.doi. org/10.1017/S001447970600425X

Mayring, P. 2010. Qualitative Inhaltsanalyse. VS Verlag für Sozialwissenschaften, Wiesbaden, Germany. http://dx.doi. org/10.1007/978-3-8349-9258-1 42

Meadowcroft, J. 2009. What about the politics? Sustainable development, transition management, and long term energy transitions. Policy Sciences 42(4):323-340. http://dx.doi. org/10.1007/s11077-009-9097-Z

Millennium Ecosystem Assessment (MEA). 2005. Ecosystems and human well-being: synthesis. Island, Washington, D.C., USA.

Miller, T. R., B. A. Minteer, and L. C. Malan. 2011. The new conservation debate: the view from practical ethics. Biological Conservation 144(3):948-957. http://dx.doi.org/10.1016/j.

biocon.2010.04.001

Muraca, B., and L. Voget-Kleschin. 2011. Strong sustainability across culture(s). Pages 187-204 in G. Bandes, G. L. Nelson, and O. Parodi, editors. Sustainable development - the cultural perspective. Edition Sigma, Berlin, Germany.

Neupane, L., J. Lienert, and S. Biber-Klemm. 2012. Sustainability of ABS and biotrade in Nepal. Pages 7-14 in S. Poudyal, P. Burger, and L. Neupane, editors. Sustainability of ABS and biotrade in Nepal: proceedings of national workshop (Lalitpur, Nepal, 30 January 2012). Center for Policy Studies and Rural Development, Kathmandu, Nepal; and University of Basel, Basel, Switzerland.

Nussbaum, M. C. 2000. Women and human development: the capabilities approach. Cambridge University Press, New York, New York, USA. http://dx.doi.org/10.1017/CBO9780511841286

Nussbaum, M. C. 2013. Creating capabilities: the human development approach. Belknap of Harvard University Press, Cambridge, Massachusetts, USA.

Ojha, H. R., N. P. Timsina, C. Kumar, B. Belcher, and M. R. Banjade. 2007. Community-based forest management programmes in Nepal: an overview of issues and lessons. Journal of Forest and Livelihood 6(2):1-7.

Olsen, C. S., and N. Bhattarai. 2005. A typology of economic agents in the Himalayan plant trade. Mountain Research and Development 25(1):37-43. http://dx.doi.org/10.1659/0276-4741 (2005)025[0037:ATOEAI]2.0.CO:2

Ostrom, E. 2009. A general framework for analyzing sustainability of social-ecological systems. Science 325 (5939):419-422. http://dx.doi.org/10.1126/science.1172133

Ostrom, E., J. Burger, C. B. Field, R. B. Norgaard, and D. Policansky. 1999. Revisiting the commons: local lessons, global challenges. Science 284:278-282. http://dx.doi.org/10.1126/ science. 284.5412 .278

Polishchuk, Y., and F. Rauschmayer. 2012. Beyond "benefits"? Looking at ecosystem services through the capability approach. Ecological Economics 81:103-111. http://dx.doi.org/10.1016/j. ecolecon.2012.06.010

Qizilbash, M. 2008. Amartya Sen's capability view: insightful sketch or distorted picture? Pages 53-81 in F. Comim, M. Qizilbash, and S. Alkire, editors. The capability approach. Concepts, measures and applications. Cambridge University Press, New York, New York, USA. http://dx.doi.org/10.1017/ CBO9780511492587.003

Robeyns, I. 2000. An unworkable idea or a promising alternative? Sen's capability approach re-examined. Centrum voor Economische Studiën Discussion Paper 30. Katholieke Universiteit Leuven, Leuven, Belgium.

Robeyns, I. 2005. The capability approach: a theoretical survey. Journal of Human Development 6(1):93-117. http://dx.doi. org/10.1080/146498805200034266

Schultz, E., M. Christen, L. Voget-Kleschin, and P. Burger. 2013. A sustainability-fitting interpretation of the capability approach: integrating the natural dimension by employing feedback loops. Journal of Human Development and Capabilities 14(1):115-133. http://dx.doi.org/10.1080/19452829.2012.747489

Scoones, I. 1998. Sustainable rural livelihoods: a framework for analysis. Institute of Development Studies (IDS) Working Paper 72. IDS, University of Sussex, Brighton, UK.

Scoones, I. 2009. Livelihoods perspectives and rural development. Journal of Peasant Studies 36(1):171-196. http://dx.doi. org/10.1080/03066150902820503

Sen, A. K. 2001. Development as freedom. Oxford University Press, Oxford, UK.

Suneetha, M. S., and B. Pisupati. 2009. Learning from the practitioners: benefit sharing perspectives from enterprising communities. United Nations Environment Programme and United Nations University Institute for the Advanced Study of Sustainability, Nairobi, Kenya.

Tvedt, M. W., and T. Young. 2007. Beyond access: exploring implementation of the fair and equitable sharing commitment in the $C B D$. International Union for Conservation of Nature (IUCN) Environmental Policy and Law Paper No. 67/2, ABS Series No. 2. IUCN, Gland, Switzerland.

United Nations Conference on Trade and Development (UNCTAD). 2011. Implications for BioTrade of the Nagoya Protocol on access to genetic resources and the fair and equitable sharing of benefits arising from their utilization. United Nations, New York, New York, USA. [online] URL: http://www.biotrade. org/ResourcesPublications/UNCTAD_DITC TED_2011_9.pdf

Valdes-Rodriguez, O. A., and A. Perez-Vazquez. 2011. Sustainable livelihoods: an analysis of the methodology. Tropical and Subtropical Agroecosystems 14(1):91-99.

World Commission on Environment and Development (WCED). 1987. Our common future. Oxford University Press, New York, New York, USA. 